\title{
HYDROELECTRIC ENERGY USING PREDICTION TECHNIQUE OF FLOOD IN RIVER "BASED ON FUZZY RULE SCHEME"
}

\author{
PANKAJ KUMAR ${ }^{1}$ \& AJAY KUMAR GUPTA ${ }^{2}$ \\ ${ }^{1}$ Department of Mechanical Engineering, GMRIT, Engineering College, Rajam, A.P. - 532127, India \\ ${ }^{2}$ Department of Mechanical Engineering, CSIT Engineering College, Drug, Chhattisgarh-491001, India
}

ABSTRACT
Flood can be used for generating Hydraulic energy so with the change in the approach of geographical study various
techniques and models are brought to the subject in the present day global context. It has become more common in
catchments study. In water resource management, flood control, land use planning and processes of ground water
management Stimulation of rainfall and discharge processes is very important. As the flood is very common and more
vulnerable for us, fuzzy guideline - based models can help to predict and forecast the flood. The discharge phenomenon of
Jiadhal basin of Dhemaji District is very complex. The factors like rainfall, soil types, vegetation etc, with their varying
characteristics, influence the volume of discharge. In this prospect, an effort is made to apply fuzzy guideline- based
model to predict and forecast the flood of Jiadhal basin.
KEYWORDS: Flood; Taguchi, Optimization; River

Received: May 20, 2020; Accepted: Jun 10, 2020; Published: Jul 24, 2020; Paper Id.: IJMPERDJUN2020439

\section{INTRODUCTION}

The rainfall and discharge process Simulation is very essential in river engineering, water resources management, flood control for consumption of surface and ground water. Simulation of the Model of rainfall and discharge process is very essential. Water discharge of basin depends on the geomorphologic properties, of the basins such as geometry, soil type and vegetation. It also effected due to climatic condition such as rainfall, temperature etc. The properties (if these aspects are not constant in discharge forecast. Despite the importance of rain water discharge there is no normally accepted 1nethod and hence reasonable rain water discharge approximations are critical for rising accurate models (if river basins. Rainfall-runoff models are nonlinear one and depend on consecutive sharing of rainfall. Thus, it is problematic to describe the response of catchment schemes with the modest model. These representations are often used for flood forecasting and reducing the damages in river basin. In recent times, calculated systems using linguistically vary to some extent than traditional numerical variables are influencing into hydro-logical revisions as well. Amongst these the presentation of fuzzy guideline-based method in modeling processes have integrate in the hydrological cycle. (Sugeno, 1993) describe the behavior of the system on by means (If natural language based (ln scheme of qualitative modeling of a fuzzy guideline based model. $\ln$ expending a fuzzy logic based method in exhibiting cause and Consequence, relations are defined orally rather than by means of known principal physical relations. A few attempts have been made so far in modelling river catchments processes and encouraging outcomes have been achieved. (Bardossy \& Disse 1993), (Hundecha et al 2001) and (Rahnama \& Barani 2005) have already established the application of such approach in modeling infiltration. The applicability in the area of meteorological data management based on model of fuzzy guideline, Abebe et al. (2000), Srinivas, 
Tripathi, Rao \& Govindan1iu (2007) and Abghai, Mahdavi, Fakherifard \& Salajegheh(2009) have shown the application for regeneration of missing rainfall events. The fuzzy based method offered here simplifies the model input by using nuer and simply assessable parameters like rainfall and Past River discharge. Moreover, fuzzy set theory developed by Zadeh (1965) is more suitable for handling the implicit vagueness in the data. The Jiadhal River is predominantly nurtured by groundwater, has minimal flow during winter season but it creates havoc during the monsoon. This necessitates flood forecast during the monsoon to save life and property in the lower part of the basin. The data used in the study are obtained from Brahmaputra Board of North Lakhimpur. The purpose of this work is to establish the approach of a fuzzy logic to implement in hydro power generation from rainfall-runoff modeling.

The study is confined to the Jiadhal basin in North East India. Jiadhal is one of the important north bank branches of the Brahmaputra tributary and covers an area of $1346 \mathrm{~km} 2$ having latitudinal and longitudinal extensions of 27008/ $\mathrm{N}$ to 27045/ N and 94015/ E to 94038/ E respectively (Figure 1.1). The basin falls within the states of Arunachal Pradesh and Assam. Out of its total basin area, Arunachal Pradesh claims $306 \mathrm{~km} 2$ i.e. 23 percent of the total basin area and rest 1040 krn2 i.e. 77 percent of the basin area belongs to the state of Assam.

\section{ALGORITHM}

\section{The Algorithm Consists of Following Steps}

- Classify each of the inputs parameter (like, mean Temperature of a month) into modules (like, low, medium etc.) as membership functions. Then the rule premises arise through combination of the input modules, one on or after each type of factor.

- Calculate the degree of fulfillment, denoted by vi(s), for each factor input parallel to the training set data and each rule $\mu$ product of the values of the membership function for the factor inputs as

$$
V I\left(A_{1}, A_{2}, A_{3}\right)=\mu i 1\left(a_{1}\right) \times \mu i 2\left(a_{2}\right) \times \mu i 3\left(a_{3}\right)
$$

- Select the number $€>0$ to such an extent that just processed DEGREE OF FULFILMENT's with esteem in any event equivalent to $€$ are taken in the development of info fuzzy numbers and the relating reaction for each standard.

- Both the information properties $\mathrm{A}, \mathrm{i}, \mathrm{k}$ and the comparing reaction $\mathrm{Bi}$ are thought to be a numbers of trilateral fuzzy for all principles I. The trilateral fuzzy numbers reaction for guideline $\mathrm{I}$ is signified by $(\beta \mathrm{i}-, \beta \mathrm{i}, \beta \mathrm{i}+) \mathrm{T}$, where $\beta \mathrm{i}$ - is the negligible response with a DEGREE OF FULFILMENT in any event $€$, and $\beta \mathrm{i}$ is the mean answer with a DEGREE OF FULFILMENT in any event $€$, and pi+ is maximal response with a DEGREE OF FULFILMENT in any event $€$. The trilateral fuzzy numbers (ai, k-, ai,k, ai,k +) Tare correspondingly decided for the contributions for guide line I. 


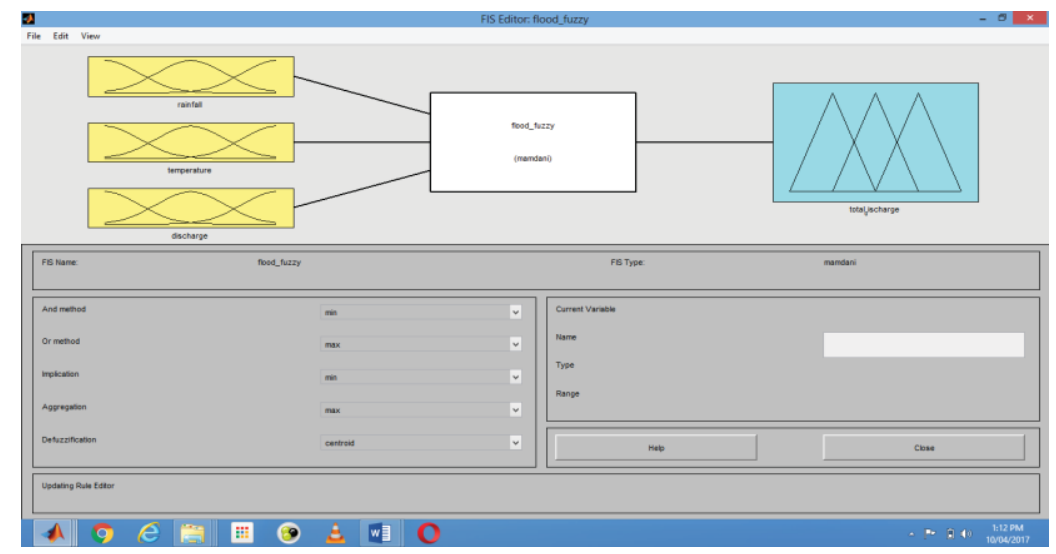

Figure 1: FIS Editor for Rainfall Membership Functions.

\section{Fuzzy Guideline-Based Discharge Methodology}

Right now, fuzzy principle based release models utilize three info premises complete month to month rainfall (R), mean month to month temperature (T) and the earlier month's release (PMD) to infer the single yield of all out month to month release. The mean month to month temperature is utilized to proportion of potential transpiration and evaporative misfortunes. The absolute earlier month's release is utilized as proportion of the potential overflow during rainfall occasions. The total monthly rainfalls together with the above two inputs decide the total discharge during the month.

The characteristics of the models based on fuzzy guideline are:

- The number of guidelines carded

- The number obtained to support the fuzzy numbers

- The DEGREE OF FULFILMENT for guideline activation

- Evaluation of the mean fuzzy answers for each guideline

The quantity of guidelines in a fuzzy based model is an element of both the quantity of info premises and the quantity of classes of each information variable. Here each of the three input variables has been classified into 3 classes, say high, medium and low giving 27 (=33) guidelines. The number of classes of each variable may also be increased to four or five classes giving a total of 64(43) or 125(53) guidelines respectively. Such increase in the number of classes will enhance the sensitivity of the model performances.

\section{Model Implementation in Jiadhal River Catchments}

Presentation and validation of the present model being handle out on the catchment area of the River Jiadhal in North East India. Every day time series data of rainfall, mean temperature and every day release esteems from 1992 to 2004 were acquired from various measuring stations on the River Jiadhal. Four unique procedures occurring in a shed framework were distinguished and a fuzzy rationale based routine was planned for every one of these procedures. The modules distinguished are: Rainfall, temperature, release and Soil water bookkeeping. A fuzzy guideline created routine was defined for every one of the modules freely of the others. The subtleties of the interpretation of the semantic guideline for the month of August are presented here for 27 guideline case. The input premises are shown for the membership functions in the Figures 2, 3, 3 and 5. 


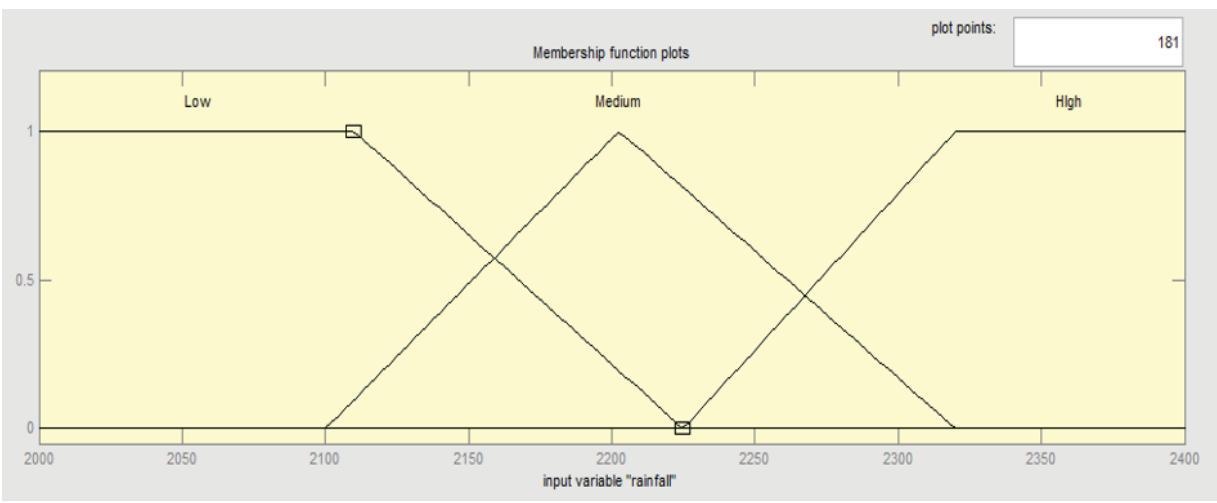

Figure 2: Rainfall Membership Functions for 27RuleCase.

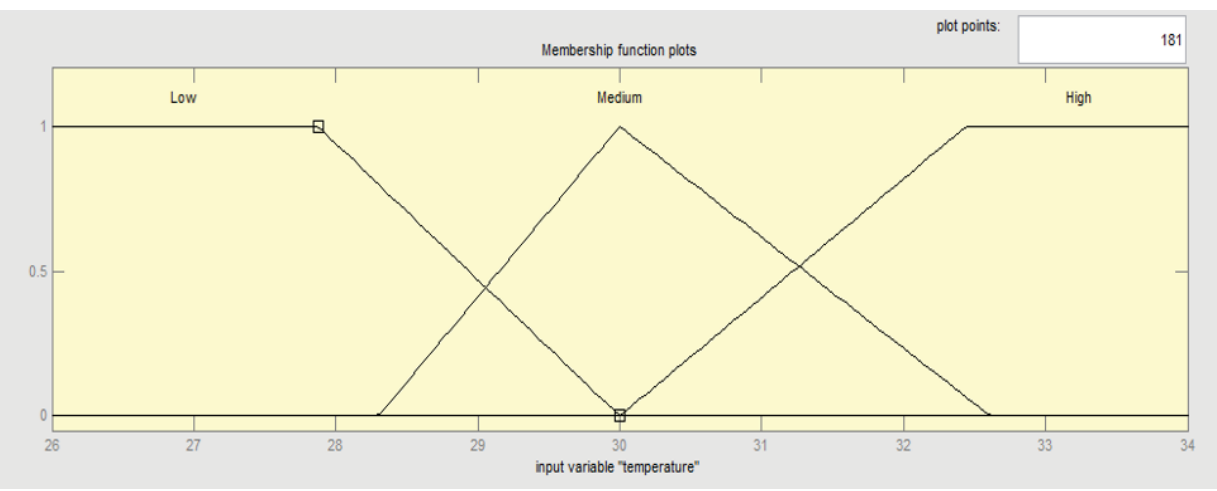

Figure 3: Temperature Membership Function for 27 Rule Case.

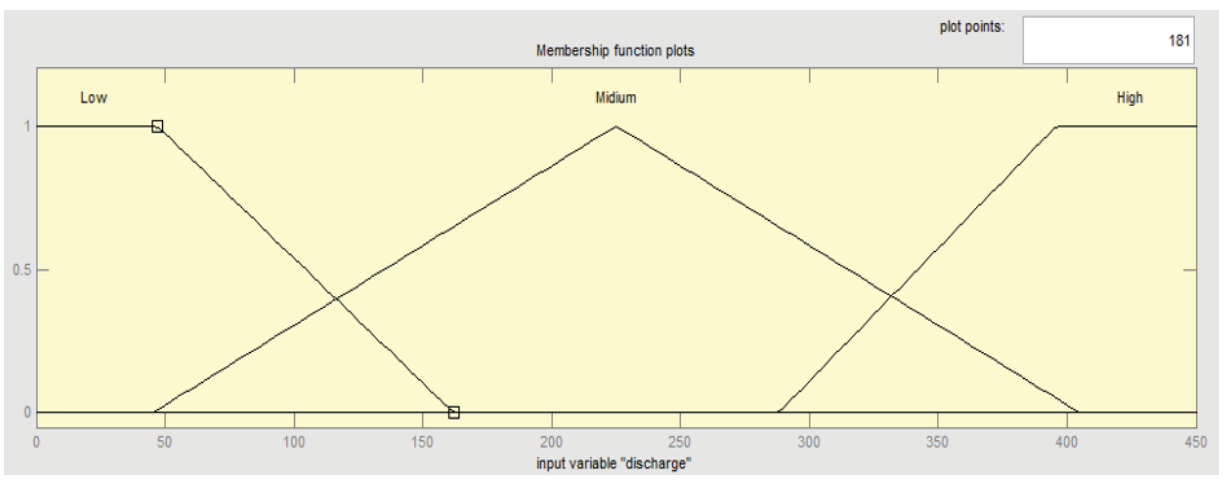

Figure 4: Previous Month Discharge or Flood for 27 Rule Case.

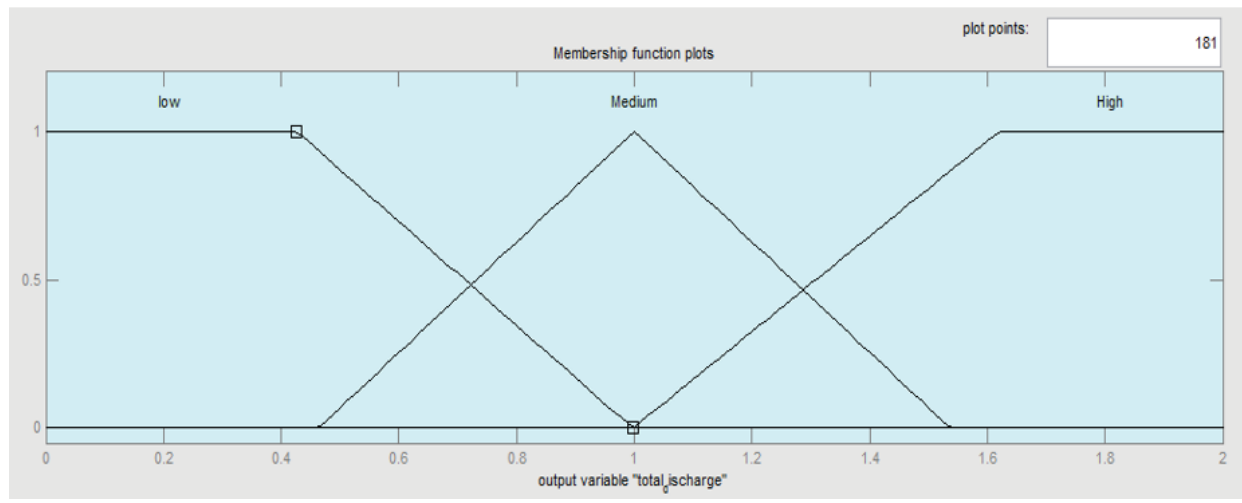

Figure 5: Soil Water Accounting. 
For each of the 3 input variables membership functional parameters are computed for the same 'August' month from 1992 to 2004. During trilling only 5guidelines were identified that fulfill the DEGREE OF FULFILMENT $(€=0.3)$. The system of guideline is established to find out the percentage (\%) of rainfall that is in the form of amount of rainfall. The contentions to be utilized in this arrangement of guidelines were recognized and were partitioned into various fuzzy classes. In the principal arrangement of guidelines where the extent of rainfall in downpour structure is resolved, the main contention is temperature and the result is extent of strong rainfall. In the second arrangement of guidelines, temperature and size of every day rainfall are utilized as contentions and the result is the day by day measure of release. The temperature esteems, extent of amassed and rainfall release were isolated into three distinctive fuzzy classes. The significances of the standard plans were fuzzified by separating the amount of release into three distinctive fuzzy classes.

Table 1: Fuzzy Classes of Total Monthly Rainfall

\begin{tabular}{|l|c|}
\hline Amount of Rainfall & Fuzzy Number of Representation (mm) \\
\hline Low & $(-\infty, 2090,2220) \tau$ \\
\hline Medium & $(2090,2220,2350) \tau$ \\
\hline High & $(2220,2350, \infty+) \tau$ \\
\hline
\end{tabular}

Table 2: Fuzzy Classes of Previous Month Discharge

\begin{tabular}{|l|c|}
\hline Previous Month Discharge & Fuzzy Number of Representation (cumec) \\
\hline Low & $(-\infty, 54,212) \tau$ \\
\hline Medium & $(54,212,370) \tau$ \\
\hline High & $(212,370, \infty+) \tau$ \\
\hline
\end{tabular}

Table 3: Fuzzy Classes of Mean Monthly Temperature

\begin{tabular}{|l|c|}
\hline Class of Temperature & Fuzzy Number of Representation $\left({ }^{\mathbf{0}} \mathbf{c}\right)$ \\
\hline Low & $(-\infty, 27.8,29.4) \tau$ \\
\hline Medium & $(27.8,29.4,31.0) \tau$ \\
\hline High & $(29.4,31.0, \infty+) \tau$ \\
\hline
\end{tabular}

Table 4: Fuzzy Classes of Percentage of Total Soil Water Accounting

\begin{tabular}{|l|c|}
\hline Relative Soil Moisture & Fuzzy Number of Representation (cumec) \\
\hline Low & $(0,0, .4, .8) \tau$ \\
\hline Medium & $(.4, .8,1,1.4) \tau$ \\
\hline High & $(1,1.4,1.8,1.8) \tau$ \\
\hline
\end{tabular}

\section{The Guidelines Obtained during Trilling are}

Guidelines 1

If total monthly rainfall is medium and mean monthly temperature is low and total previous month discharge is medium, then total monthly discharge is in trilateral fuzzy number.

Guideline 2

If total monthly rainfall is low and mean monthly temperature is medium and total previous month discharge is medium, then total month.ly discharge is in trilateral fuzzy number.

Guideline 3

If total monthly rainfall is medium and mean monthly temperature is medium and total previous month discharge is low, then total monthly discharge being some trilateral fuzzy number. 
Guideline 4

If total monthly rainfall is medium and mean monthly temperature is medium and total previous month discharges medium, then total monthly discharge is some trilateral fuzzy number.

\section{Guidelines 5}

If total monthly rainfall is medium and mean monthly temperature is medium and total previous month discharge is high, then total monthly discharge is some trilateral fuzzy number.

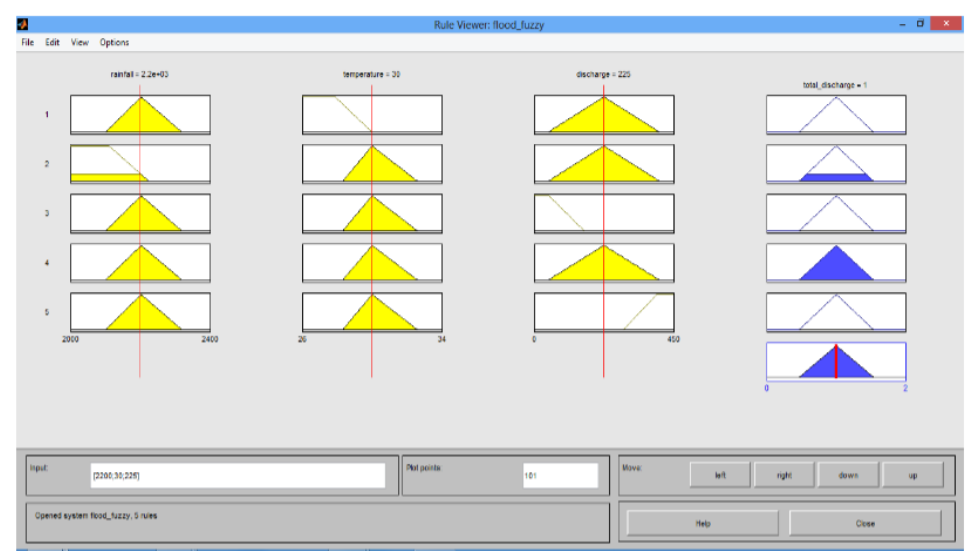

Figure 5: Guideline Viewer for Prediction Rainfall and Runoff.

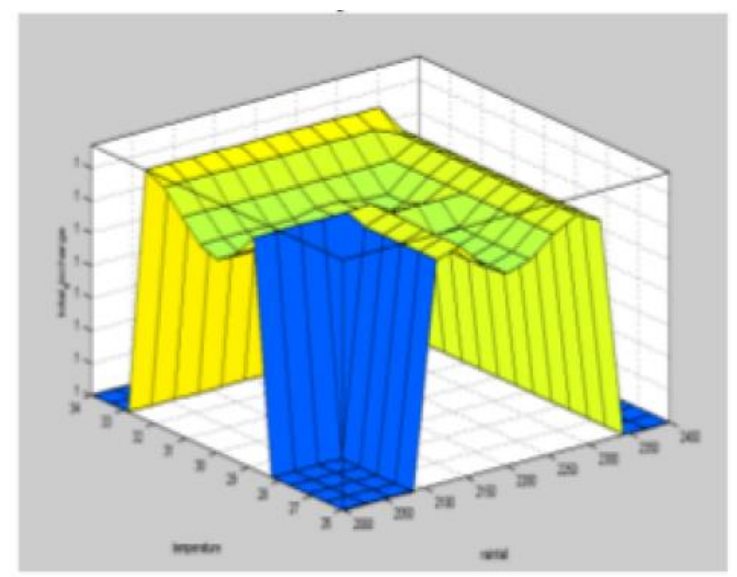

Figure 6: Surface Viewer for Prediction Rainfall and Runoff.

As shown in Fig-5 and Fig-6 the guideline and surface viewer flood forecasting. Fig-5 also represents the predicted data for validating the data with statically data. This model investigates the elements of the made run-off, and along these lines it's gracefully in time once the water balance is fixed by the modules for spillover and rainfall.

\section{CONCLUSIONS}

Before analysis the pertinence of the fuzzy logic created procedures for the different catchments methods, the Hydrological behavior (HBV) models was standardized and utilized for the basin. The applied parameters of the framework which is utilized in the HBV models (Barnstorm, 1995) was adjusted to use in a fuzzy rationale based daily practice. Because of the unforeseen idea of the entire bowl, the guidelines that apply for single piece of the bowl would not use to various pieces of the bow I. This would require the plan of some different arrangement of guidelines for each sub-bowl, which would be difficult to deal with. Fuzzy guideline based routine was distinguished to show the better execution of the framework. For 
applying such kind of approach, a superior data of the key physical methods isn't essential. Just data of the reasons that impact the strategies and the subjective relations between the reason and impacts are required. Each factor can have various qualities for various zones of the model area. As the model requirements are not considered in a fuzzy guideline based demonstrating approach, it makes the methodology simpler and quicker to work with.

\section{REFERENCES}

1. Abebe, A. I,Solomatine, D. P. \&Venneker, R. G. W. (2000) Application of adaptive fuzzy rule-based models for reconstruction of missing precipitation events. Hydrol. Sci. J. 45(3), 425-436.

2. Anandh, T., and R. Vinoth. "A Comprehensive Assessment of Small Hydro Power in India-Current Scenario and Future Potential." International Journal of Mechanical and Production Engineering Research and Development 8.3 (2018): $413-424$.

3. Bardossy, A. \& Duckstein, L. (1995) Fuzzy Rule-Based Modeling with Applications to Geophysical, Biological, and Engineering Systems. CRC Press, Inc., Boca Raton, Florida,USA.

4. Bergstrom, S. (1995) The HBV model. In: Computer Models of Watershed Hydrology (ed. by V. P. Singh), 443^176. Water Resources Publications, Littleton, Colorado,USA.

5. Coppla Jr., E.A., et.al., Fuzzy rule-based methodology for estimating monthly groundwater recharge in a temperature watershed, Journal of Hydrologic engineering, July-August,2002.

6. Gupta, H. V. \& Sorooshian S. (1998) toward improved calibration of hydrologie models: multiple and noncommensurable measures of information. Wat. Resour. Res. 34(4), 751-763.

7. Hundecha, Y., et.al., Development of a fuzzy logic-base rainfall-runoff model, hydrological Sciences -Journal-des Sciences Hydrologiques, 46(3),June, 2001.

8. Klir, J.G., and Yuan Bo, fuzzy Sets and Fuzzy logic, Theory and Application, PHI Private Ltd., New Delhi,2000.

9. Lata, Renu, et al. "Impact analysis of run-off-the river type hydroelectric power plants in Himachal Pradesh, India." Int. J. Civil Struct. Environ. Infra Struct. Eng. Res. Dev 3.2 (2013): 77-82.

10. Mahabir, C., et.al., application of fuzzy logic to forecast seasonal runoff, Hydrological Process, 17, 3749- $3762,2003$.

11. Shantika, Tito, Tri Sigit Purwanto, and Martin Garnida. "Design Rotor Turbine Hybrid of Pv-Picohydro Power Plant as Energy Sources for Rural Area in Indonesia." International Journal of Mechanical and Production Engineering Research and Development (IJMPERD) 10.3 (2020).

12. See, L. \& Openshaw, S. (1999) Applying soft computing approaches to river level forecasting. Hydrol. Sci. J. 44(5), 763-778.

13. See, L. \& Openshaw, S. (2000) A hybrid multi-model approach to river level forecasting. Hydrol. Sci. J. 45(4),523-536.

14. Sugeno, M. \& Yasukawa, T. (1993) A fuzzy-logic-based approach to qualitative modeling. IEEE Trans, on Fuzzy Systems $1(1), 7-31$.

15. Singh, A. N. A. N. D., and P. R. A. S. H. A. N. T. Baredar. "A technical, economic, and environmental performance of hybrid (solar-biomassfuel cell) energy system." International Journal of Environment, Ecology, Family and Urban Studies (IJEEFUS), 6 (5), 1726 (2016).

16. Zadeh, L. A. (1965) Fuzzy sets. Information and Control 8(3), 338-353.

17. Zadeh, L. A. (1973) Outline of a new approach to the analysis of complex systems and decision processes. IEEE Trans. Systems,

Man,

and

Cybernetics. 

